\title{
Investigation of the Influence of Relative Humidity on the Two Air Curtains in Multi- Deck Display Cabinet
}

\author{
Mostafa A. Abdel-Baky*, Shedeed H. ShamsEl-Dein* and Tareq E. Shalma** \\ *Dept. of Mech. Power Engineering, Faculty of Engineering \\ Minoufiya University, Shebin El-kom, Egypt \\ **Production Manager, Fricool Refrigeration Industry Company
}

\begin{abstract}
The air curtains are used as a seal to prevent the infiltration through display cabinets and consequently energy is decreased. The relative humidity plays an important role in cooling load of display cabinets. This work aims to present an experimental and numerical study of the influence of ambient relative humidity on the two air curtains in multi-deck display cabinet at different temperature and comparing the results with a single air curtain. For validation, the present work results are obtained by using computational fluid dynamics (CFD) code (Fluent6) and compared with previous researches.
\end{abstract}

Keywords: Air curtain, Vertical refrigerated multi-deck, Plane free jet, Heat and mass transfer through air curtains.

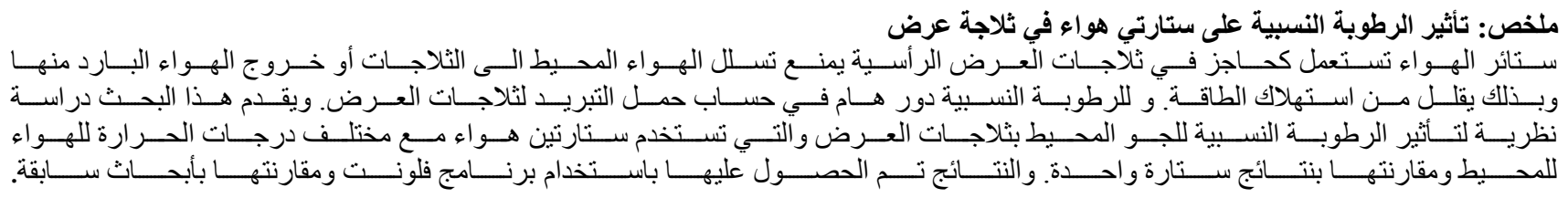

\section{1- Introduction}

When a refrigerated display cabinet operates in a store, it exchanges heat and moisture with its environment. The moisture exchange between the display cabinet and the store environment is the most casing difficulty for the satisfactory operation of the display cabinet. This is because it causes high energy requirements for maintaining a satisfactory temperature within the display cabinet. There is a direct interaction between display cabinet refrigerator and the conditioning systems in supermarkets. High relative humidity in the conditioned space produces more condensation on the display cabinet walls and product. Consequently, more frost may be formed on the refrigeration evaporator coils. The removing of this additional frost requires defrost cycle which resulting in higher energy use. To avoid condensation on the display cabinet walls and/or doors requires anti-sweat heaters which resulting in higher energy consumption. It is clear that dry air may cause less frost formation and condensation in the display cabinet. This tends to reduce the use of energy due to the reduction of frosting and hence less defrosting. Also the use of anti-sweat heater is reduced. In that case, the heat transfer and the load on the case will be minimized.
Air curtains are devices used in refrigerated display cabinets and doorway of air conditioned spaces to reduce the exchange of heat, moisture and contaminants between the display cabinet and the surrounding and consequently energy costs are reduced.

Cold-air distribution can be forced or naturally circulation depending on the kind of foodstuff. Forced air circulation is preferable because it is much more effective in transferring the refrigerating power and enables the correct operation of almost every kind of display cabinet

In a vertical open display cabinet which uses one or two air curtains, the air curtain creates a nonphysical barrier between the cold air in the cabinet and the ambient air. In inner air curtain, the air is forced by propeller fans to flow through an evaporator at the bottom of the cabinet. The outer air curtain, entrained ambient air, and spill to the ground. The inner air curtain is re-cooled by the evaporator while the outer air curtain bypasses the evaporator in the air flow tunnel. This makes the temperature of the inner air curtain lower than that of the outer air curtain.

The entrainment of warm air from the environment causes the air curtain to become warmer as it passes down the cabinet. Entrainment causes the mass 
flow rate of the air curtain to increase as it moves down the front of the cabinet. Portion of outer air curtains will overspill onto the floor as mentioned previously. This air is colder and heavier than the ambient air. So, it stays on the floor, causing a customer comfort issue which is commonly termed the "cold feet effect".

All the above parameters are functions of the design and application of the air curtain. In most cases, the prediction of their performance in standard applications depends on information supplied by the manufacturer. A number of mathematical models have been developed to aid the design and performance prediction of air curtains. Major contributions to the work include those of Hetsroni [1], Hayes [2] and Van [3].

Hetsroni [1] worked with a recirculatory type air curtain and developed an entrainment spill model to calculate the heat transfer through the air curtain. His simulation results were taken to predict the heat transfer with an accuracy of $20 \%$ compared to experimental measurements. Hayes [2] investigated heated nonrecirculated air curtains. He developed a model to predict the total heat transfer across the air curtain and used it to investigate the effect of various design parameters such as jet angles, initial velocities and jet temperatures on heat transfer characteristics. Similar to Hetsroni's model, Hayes' model assumed low initial turbulence intensities, less than $1 \%$, and uniform initial velocity profiles. Following to Hayes' work, Van [3] developed a model to investigate the influence of the initial turbulence intensity of heat and mass transfer through an air curtain. The experimental and modeling results showed that, the initial turbulence intensity would have little effect on the heat and mass transfer through long air curtains when curtain length to jet width ratios above twenty. For length to width ratios less than 10 , it would be considerable and could not be neglected.

The model developed by Van [3] was subsequently applied by Howell [4] to investigate heat and moisture transfers across air curtains employed on refrigerated display cabinets. Tests carried out on two different air curtain lengths at different room and display cabinet conditions showed differences between computed and measured heat transfers of between $0.7 \%$ and $26.5 \%$. The reasons for the errors were not reported but measurement errors would have a significant effect on the overall accuracy of the results.

Hammond et al. [4] used recirculating cold air curtains to seal the open front of all multi-deck refrigerated display cabinets commonly used in food retail. Infiltration through the air curtain has been estimated to be the source of between 78 and $81 \%$ of the total heat gain to the cabinet. More efficient air curtains would not only save energy, but would enable more precise temperature control of the produce within the display cabinet better preserving food quality.
Curtain thickness, length, discharge temperature and velocity all influence the efficiency of the air curtain had been discussed.

Neto et al. [5] studied the different methods of characterizing the aerodynamic sealing effect provided by an air curtain device placed over the opening between two spaces. Yu et al. [6] simulated the flow and heat transfer characteristics of air curtains in a vertical display case with a two-fluid turbulence model. The simulation results based on the two-fluid model are compared with experimental data. The comparison results showed that the two-fluid model enables to predict thermal stratification phenomenon more accurately and shows better agreement with the measured values than the $\mathrm{k}-\varepsilon$ model. Ryu et al [7] used ANSYS CFX for computations of the air flow inside the tunnel. Three cases were analyzed depending on the installing location of the air curtain. The computational results of the air-curtain installed tunnel become the basis for the optimum design study. Bokel [8] performed CFD-calculations to separate a non-smoking zone from a smoking zone using an air curtain.

To date, most researches on refrigerated display cabinets focused on computational fluid dynamics (CFD) simulation and experimental studies mainly concentrated on the effects of air supply velocity and initial turbulent intensity on the development of an air jet for one air curtain or two air curtains separately. The main objective of the present work is the study of the influence of different ambient relative humidity on vertical multi-deck open cabinet using two air curtains at different ambient temperatures and comparing the results with a single air curtain. For validation, the present work results obtained by using computational fluid dynamics (CFD) code (Fluent6) and are compared with previous researches.

\section{Description of flow patterns}

The flow patterns of one and two parallel air curtains are shown schematically in Figs. (1) and (2). For one air curtain, flow is divided into three regions, potential core region, transition region and developed region, see Fig. (1). The characteristic of the potential core region is that the centerline velocity is almost constant and equal to the outlet velocity $\mathrm{u}_{\mathrm{o}}$. Also the turbulence intensity is constant. The length of this zone is about 5:8 times the jet thickness $b_{o}[1]$.

As a result of the combined entrainment between the two jets of air curtains, a sub-atmospheric pressure region is formed close to curtain outlet. The subatmospheric pressure causes individual jets, which known as the converging region, see Fig. (2). The two potential cores of the two air curtains combine at merging point where the centerline velocity is zero. This point is called merging point. 


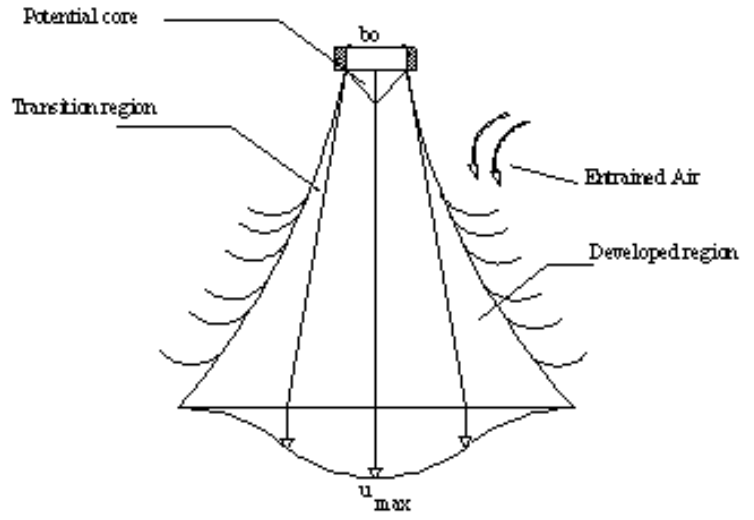

Fig. (1) Flow patterns of one air curtain

Downstream from the merging point, in the merging region, the two air jets continue to interact with each other and the centerline velocity increases until it reaches a maximum value at the combined point. Downstream from the combined point, the two air jets combine together to be like a single free jet flow.

Transition region starts with the velocity decay and the amplification of the jet expansion. It generally starts after approximately $5 b_{o}$ from the jet outlet. Developed region velocity decay remains constant. Velocity decay is expressed with non-dimensional quantities. It generally starts after approximately $20 b_{o}$ from the jet outlet [1].

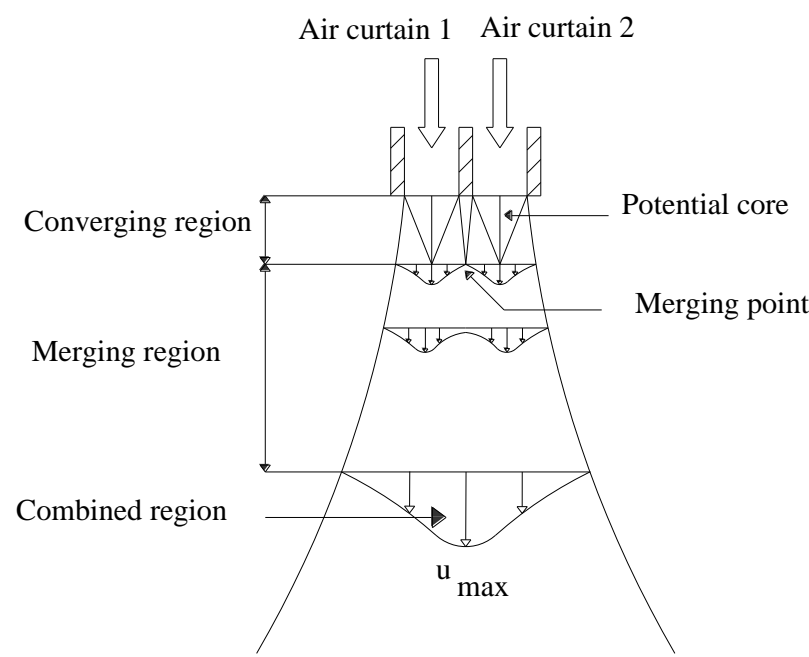

Fig. (2) Flow patterns of the two parallel air curtains

In a vertical open display cabinet which uses two air curtains, for inner air curtain, the air is forced by propeller fans to flow through an evaporator at the bottom of the cabinet. Cooled air is fed into the cabinet through the back panel of the cabinet, and then it is blown through two honeycombs to form two air curtains. The outer air curtain entrains ambient air and spills it to the ground. The inner air curtain is re-cooled by the evaporator while the outer air curtain is bypassed across the evaporator in the air flow tunnel, which makes the temperature of the inner air curtain lower than that of the outer air curtain. The air flow from the perforated back panels can provide cooling for the rear products to avoid cold curtains being prevented by front products. In addition, it can also support the flow of vertical air to perform better insulation performance.

\section{Mathematical model formulations}

The following analysis describes the energy flows in a vertical display cabinet. The input data for the analysis is based on the numerical results. The results of velocity, temperature and humidity ratio distributions will be used to evaluate both sensible and latent heat transfer rates through one air curtain and two air curtains. Also, the selection criteria of dimensions and flow parameters are described. Figure (3) illustrates the various heat transports in a vertical cabinet, and whether they are affected by the dry bulb temperature or the moisture content of the ambient air.

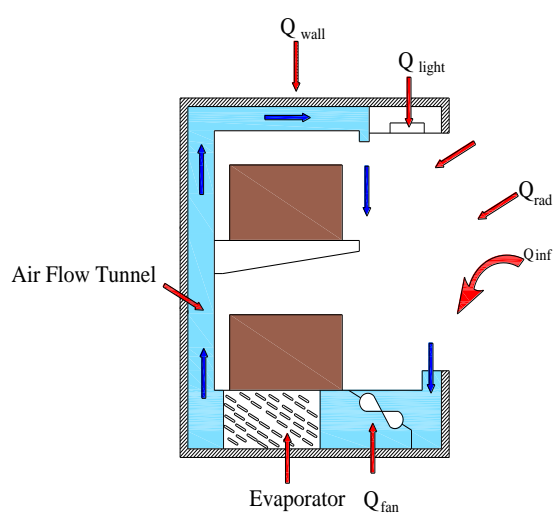

Fig. (3) The various heat transport in vertical cabinet display

\section{1 Display case model}

The following model can be used to describe the heat inputs that contribute to the energy flows in a vertical display cabinet. All calculations are based on stationary conditions, with measured values being in the form of time mean values.

$$
\begin{aligned}
\dot{Q}_{\text {case }}= & {\left[\dot{Q}_{c}+\dot{Q}_{R}+\dot{Q}_{i s}+\dot{Q}_{L}+\dot{Q}_{F}+\dot{Q}_{D}\right.} \\
& \left.+\dot{Q}_{A S H}+\dot{Q}_{\text {pulldown }}\right]_{\text {sensible }}+\left[\dot{Q}_{i l}+\dot{Q}_{\text {pr }}\right]_{\text {latent }}
\end{aligned}
$$

The cooling load of a typical display cabinet has both sensible and latent components. Conduction through the floor, top and back of the cabinet is a function of the length of the cabinet, which is not the case for conduction through the ends. Heat input from external lighting, and radiation exchange from other surrounding surfaces in the shop are separated. Heat input caused by defrosting is calculated as a mean value of all defrosting cycles during one operating cycle, which is 24 hours. Once the display case overall heat transfer coefficient is determined, the transmission load can be quantified using Eq. (2).

$\dot{Q}_{c}=U A\left(T_{\text {room }}-T_{\text {case }}\right)$ 


\section{1. 1 Pull-down load}

Pull-down load due to product shelving comes from delivering products into the case at a temperature higher than the designed storage temperature. It is the amount of cooling required to decrease the product temperature to a desired target temperature, Eq. (3).

$Q=m C_{P}\left(T_{S}-T_{f}\right) / \Delta \tau$

\section{1. 2 Post-defrost pull-down load.}

The auxiliary defrost heat added to the evaporator must be removed once compressors operate at the end of the cycle.

$$
\dot{Q}_{p d}=m C_{P}\left(T_{p d}-T_{i}\right) / \Delta \tau
$$

\section{1. 3 Anti-sweat heater load}

Anti-sweat heaters are used on most low temperature open display cases as well as reach-in type cases with glass doors. These electric resistance heaters are located around the case handrails and door frame/mullions to prevent condensation on metal surfaces. They also reduce fogging of the glass door that can hurt product merchandising. Anti-sweat heaters typically operate continuously. Their power usage and resulting cooling load often can be reduced by applying smart controls than can reduce heater operation depending on indoor humidity. Equation (5) gives the cooling load contribution of anti-sweat heaters.

$$
Q_{\text {ASH }}=k_{1} W
$$

\section{1.4 Internal loads}

The display case internal load includes the heat from the display cabinet lights and the evaporator fan motors. The lamps, ballasts, and fan motors are typically located within the thermodynamic boundary of the cabinet. Hence, in most cases, their total heat dissipation should be considered part of the case load. The fan motor heat gain is a direct function of flow work and combined motor fan efficiencies. Flow work is also a function of air velocity, discharge opening dimensions and total pressure loss across the coil. For load calculations, however, simply the nameplate horsepower and the rated wattage of lamps and ballasts could be used in Eqs. (6) and (7).

$$
\begin{aligned}
& \dot{Q}_{f a r}=k_{1} W_{f a n} \\
& \dot{Q}_{\text {light }}=k_{1} W_{\text {light }}
\end{aligned}
$$

The latent portion refers to the heat content of the moisture added to the display cabinet by the room air drawn into the case through the air curtain. As air passes through the evaporator, it loses its sensible heat and it is dehumidified. The sensible infiltration load is given by Eq. (8).

$$
\dot{Q}_{\text {inf }}=\rho \dot{V} C_{P} k\left(T_{\text {room }}-T_{\text {case }}\right)
$$

The main source of latent load for a display cabinet is the moisture content of the ambient air that is entrained into the display cabinet across the air curtain. In some cases, product respiration generates additional moisture within the display cabinet. Equation (9) calculates the latent load of the fixture.

$$
\dot{Q}_{L}=\dot{Q}_{i l}-\dot{Q}_{p r}
$$

The infiltration portion of the cabinet display latent load can be determined by:

$$
\dot{Q}_{i l}=\left[\rho V\left(\omega_{\text {room }}-\omega_{\text {case }}\right)\right] h_{f g}
$$

Fresh fruits and vegetables lose moisture by respiration. This moisture transports through the skin of the goods, evaporates and ends up in the surroundings by convective mass transfer. The generated heat increases the water vapor dissipation across the skin of goods in the refrigerated display cabinet. This cooling load can be estimated by the following equation:

$Q_{p r}=n m_{v} A_{s} h_{f g}$

Finally, heat from radiation is neglected because it is very small and there was no solar radiation in the room.

\section{Experimental Setup}

The apparatus on which the experimental work has been conducted was built in heat engine laboratory, Faculty of Engineering at Shebine El-Kom, Egypt. It was a single deck, vertical viewer refrigerator that shown in Fig. (3). The unit consists of a vertical cabin supplied with a refrigeration unit. The cabinet was made of steel - polyurethane panel. The outer and inner sides of the cabin were made of $1 \mathrm{~mm}$ wall thickness steel sheet. The polyurethane insulation used was of $50 \mathrm{~mm}$ thickness and it has thermal conductivity of 0.025 $\mathrm{W} / \mathrm{m} . \mathrm{K}$. 


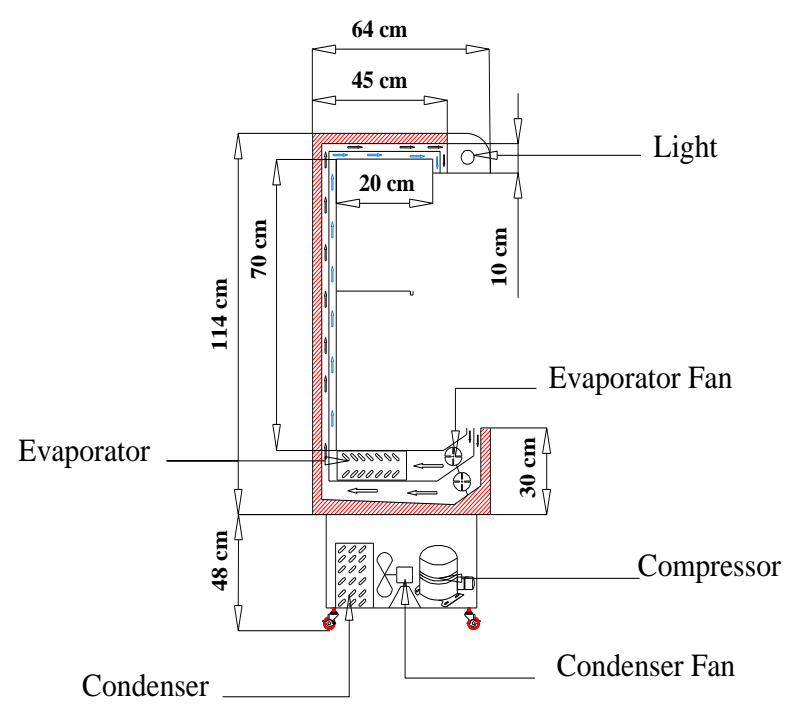

Fig. (3) Test section

The refrigeration unit consists of an evaporator, a compressor of $550 \mathrm{~W}$ power, a condenser and an expansion device. The outer dimension of the display cabinet is $1.52 \mathrm{~m}$ height, $0.74 \mathrm{~m}$ width, $0.64 \mathrm{~m}$ depth. Two fans were installed to provide the required air in the cabinet, one of them was fixed before the evaporator in first duct while the last one was fixed inside the second duct. The air curtain width were 13 and $5 \mathrm{~cm}$ for both one and two air curtains. The back panel width and top ceiling gap were $50 \mathrm{~mm}$.

The test section was installed inside an isolated room of $2.5 \times 1.5 \times 2 \mathrm{~m}$. The room was made of steelPolyurethane panel with $5 \mathrm{~cm}$ insulation. It was supplied with a split air conditioning unit of $1.125 \mathrm{~kW}$ electric power consumption, a humidifier, electric heater and relative humidity and temperature controls and to maintain the inside room at the required various test conditions as defined by the ISO test standard.

In order to measure the temperature distribution inside and outside the display cabinet, thermocouples of K-type were distributed inside it as shown in Fig. (4). The measuring range of that type is $-50^{\circ} \mathrm{C}$ to $200^{\circ} \mathrm{C}$. The thermocouples were checked for damage before installation. The output signals of the thermocouples were transferred to a digital temperature indicator set. The relative humidity was measured by digital hegrostate at the same locations of temperature measurement. A cup anemometer was also used to measure the air flow velocity at the same locations.
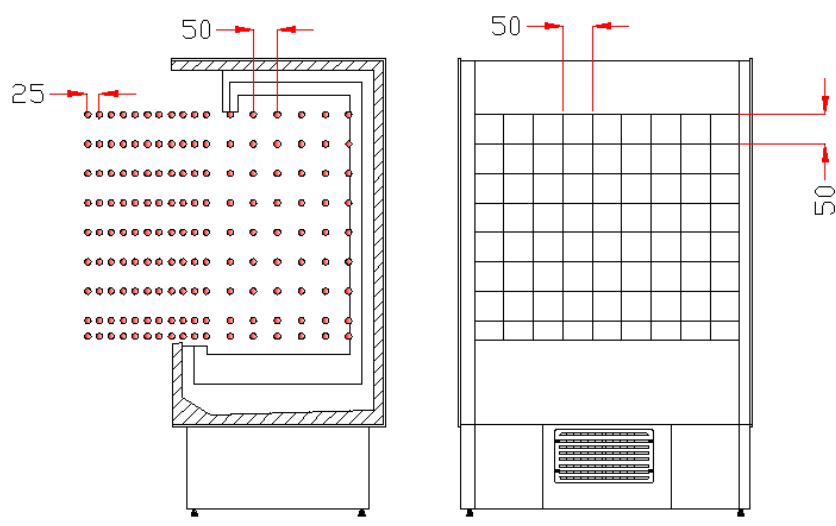

Fig. (4) Positions of measuring the velocity, temperature and relative humidity of air.

Table (1) gives the values under a typical display case operation condition.

Table (1) Principal parameters of the display case

\begin{tabular}{|l|c|}
\hline Parameters & Values \\
\hline Display case width $\mathrm{W}(\mathrm{m})$ & 0.61 \\
\hline Display case height $\mathrm{H}(\mathrm{m})$ & 0.45 \\
\hline Inner air curtain width $\mathrm{b}_{\mathrm{o}, \text { in }}(\mathrm{m})$ & 0.03 \\
\hline Outer air curtain width $\mathrm{b}_{\mathrm{o}, \text { out }}(\mathrm{m})$ & 0.03 \\
\hline Ambient temperature $\mathrm{T}_{\mathrm{a}}\left({ }^{\circ} \mathrm{C}\right)$ & 20 \\
\hline Ambient relative humidity $(\%)$ & 45 \\
\hline Outer air curtain velocity $\mathrm{u}_{\mathrm{o}, \text { out }}(\mathrm{m} / \mathrm{s})$ & 0.69 \\
\hline Inner air curtain velocity $\mathrm{u}_{\mathrm{o} \text { in }}(\mathrm{m} / \mathrm{s})$ & 0.69 \\
\hline Outer air curtain temperature $\mathrm{T}_{\text {out }}\left({ }^{\circ} \mathrm{C}\right)$ & 4.4 \\
\hline Inner air curtain temperature $\mathrm{T}_{\text {in }}\left({ }^{\circ} \mathrm{C}\right)$ & 11 \\
\hline
\end{tabular}

The computer program, FLUENT 6.2 was used to solve the time-independent (steady state) conservation equations together with different turbulence models, and the corresponding boundary conditions. The numerical solution grid divided the space of the cold room into discretized computational cells of the order of 500,000 tetrahedral cells. Solution convergence criteria, was applied at each iteration and ensured the summations of normalized residuals were less than $10^{-4}$ for flow, $10^{-4}$ for $\mathrm{k}$ and $\varepsilon$, and $10^{-6}$ for energy.

\section{Results and discussion}

Figure (5) indicates a comparison of predicted velocity distribution $\mathrm{u} / \mathrm{u}_{\mathrm{o}}$ between the experimental work and four numerical models, they are; k- $\varepsilon$ model and $\mathrm{k}-\Omega$ model, laminar model and Reynolds stress model (RSM). Laminar model is less accurate because the flow may be more turbulent in this region. The other three of the turbulence models predicted this velocity gradient much better. The theory of turbulent jets suggests that an initial region of the jet exists before the turbulence region (laminar region due to honeycomb). As the air curtain develops downstream of the outlet, the centerline velocity decays and the pattern of the air flow spreads. It then follows that small eddies in the 
flow direction into larger ones increasing the length scale and resulting in a higher Reynolds number. It seems, therefore, that the flow is becoming more turbulent. Both $\mathrm{k}-\varepsilon$ and $\mathrm{k}-\Omega$ models provided the best prediction of the velocity profile at mid of air curtains. $\mathrm{k}-\varepsilon$ model is chosen for this present work as it is more accurate and it was used in most previous researches.

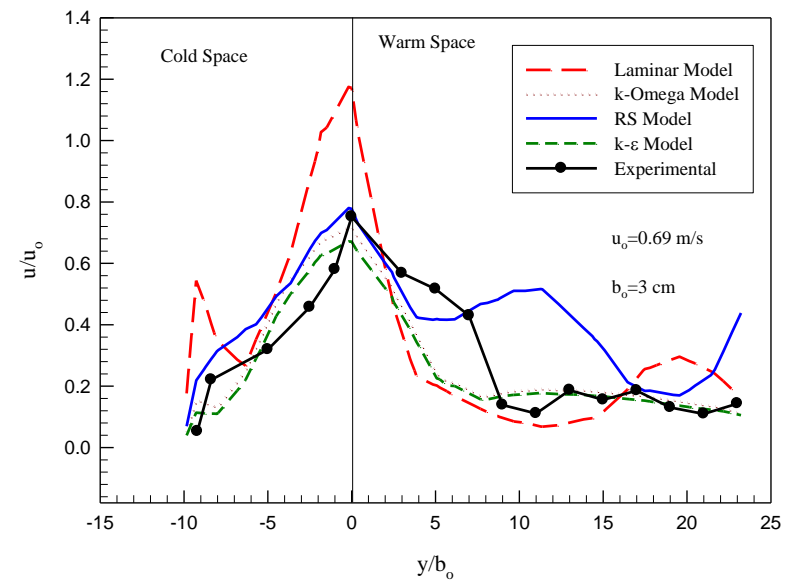

Fig. (5) Comparison of velocity profiles at $\mathrm{x} / \mathrm{b}_{\mathrm{o}}=12$, two air curtains.

\section{1 Effect of relative humidity on velocities distribution through two air curtains}

Figures (6) through (8) show the effect of the relative humidity on velocities distribution through two air curtains. It is noticed that,there is no effect of the relative humidity on the velocity distribution due to stable of temperatures (test room temperature, air curtains temperature and refrigerator temperature). So, the density of air did not change as humidity increased. This mean that, the relative humidity has no affect on the velocity distributions at this case. Velocity increases in dry air while it is nealy constant in humid air, at the same temperature.

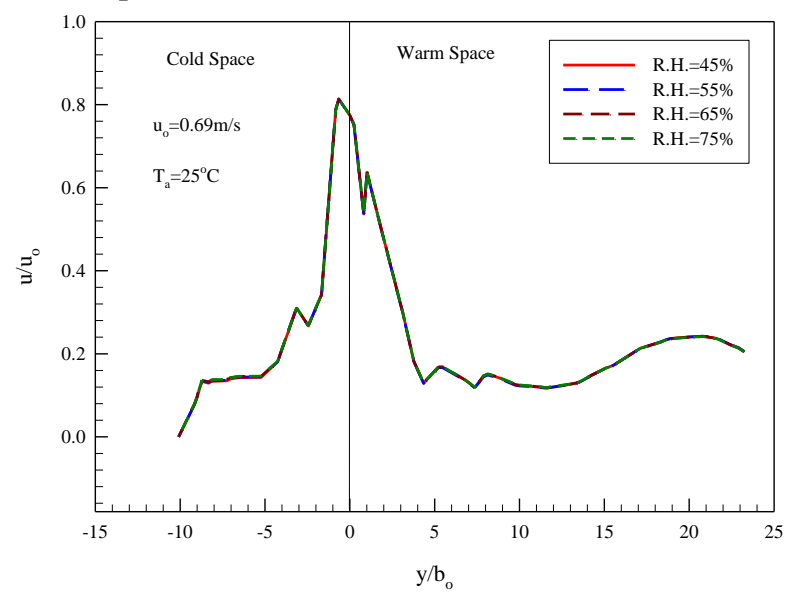

Fig. (6) Effect of relative humidity on velocity distribution through two air curtains, $x / b_{0}=6$

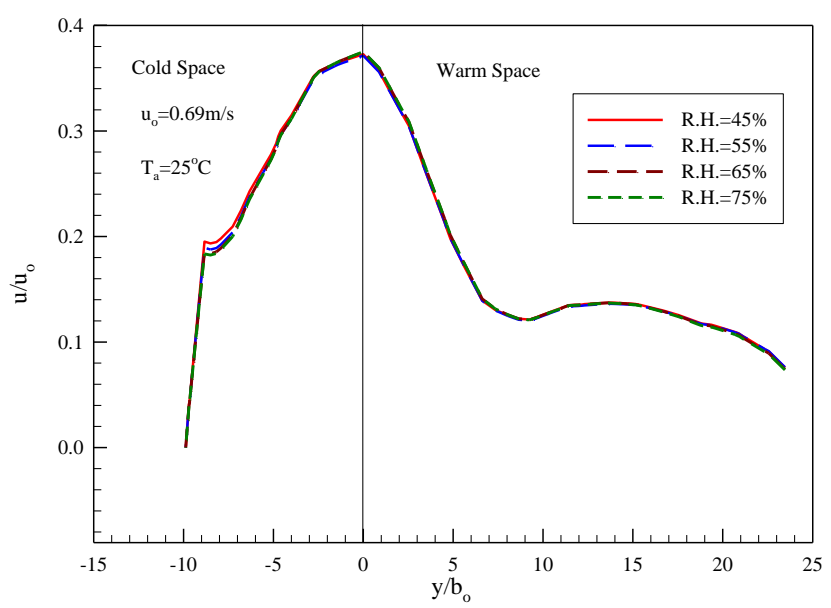

Fig. (7) Effect of relative humidity on velocity distribution through two air curtains, $\mathrm{x} / \mathrm{b}_{\mathrm{o}}=12$

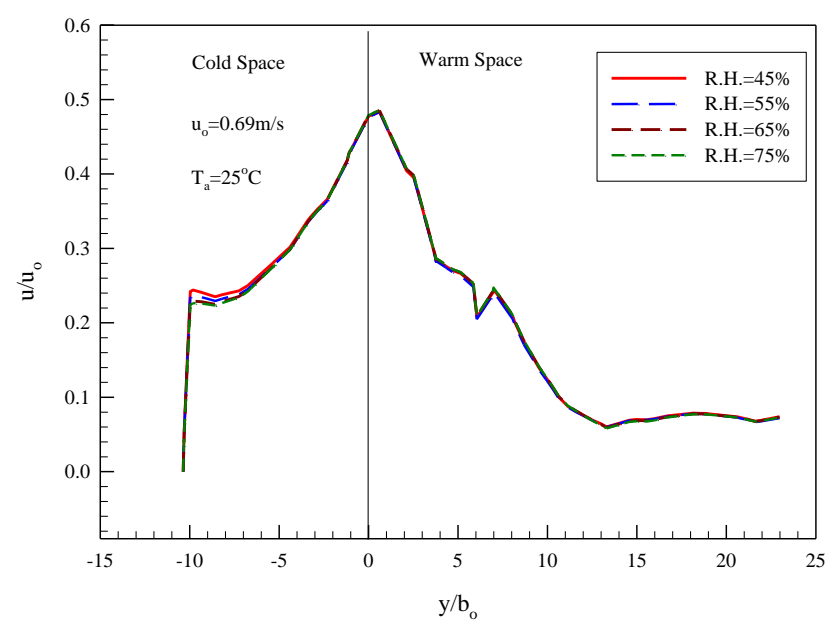

Fig. (8) Effect of relative humidity on velocity distribution through two air curtains, $\mathrm{x} / \mathrm{b}_{\mathrm{o}}=22$

\section{2 Effect of relative humidity on the inside temperatures distribution through two air curtains}

Figures (9), (10) and (11) represent the effect of ambient relative humidity on the inside temperatures in the refrigerator cabinet using two air curtains. The relative humidity has very little effect on the inside temperatures of the cabinet (as ambient temperatures were constant). The temperature inside the cabinet at different ambient relative humidities was increased as $\mathrm{x} / \mathrm{b}_{\mathrm{o}}$ was increased. This is because of the air entrainment and mass flow rate throw outlet of discharge of air curtains. Those affect on the temperature inside the refrigerator cabinet. The ambient relative humidity is an important factor as it is affect on the cold space, which in turn affect on the cooling products. 


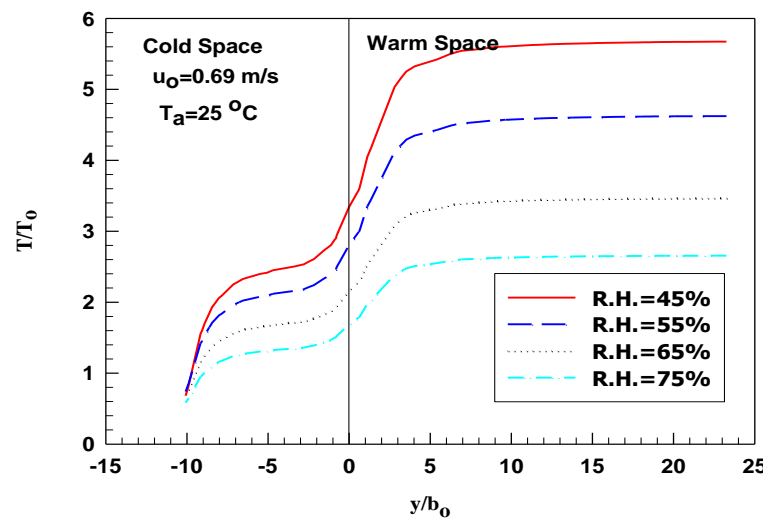

Fig. (9) Effect of relative humidity on temperatures distribution through two air curtains, $x / b_{0}=6$

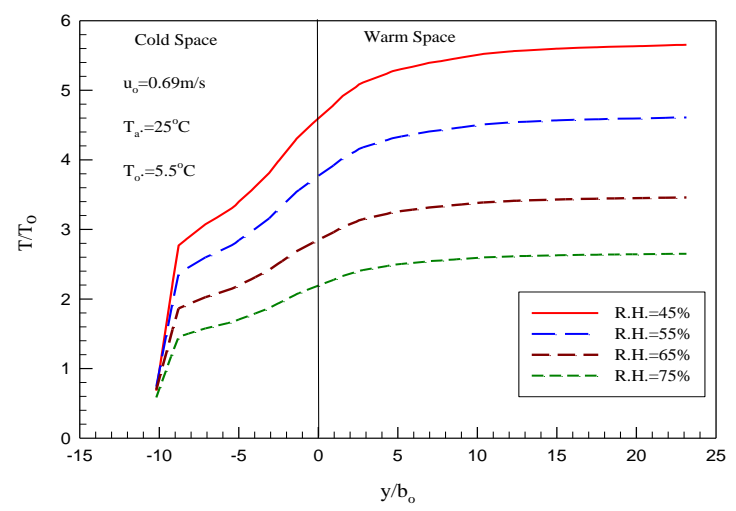

Fig. (10) Effect of relative humidity on temperatures distribution through two air curtains, $x / b_{0}=12$

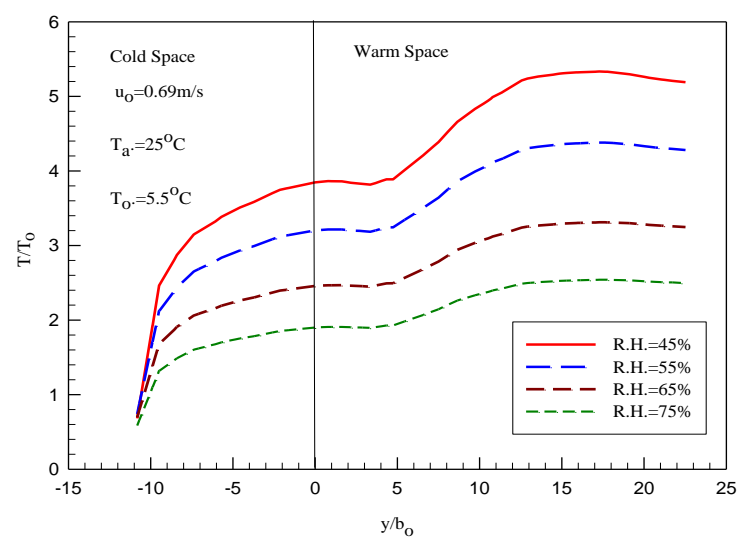

Fig. (11) Effect of relative humidity on temperatures distribution through two air curtains, $x / b_{0}=20$

\section{3 Effect of the ambient relative humidity on the humidity ratio distribution through two air curtains}

Figures (12), (13) and (14) illustrate the effect of relative humidity on the humidity ratio for different values of $x / b_{0}$ and $y / b_{o}$ at constant ambient temperature through two air curtains. It is shown, that, as the relative humidity is increased, a slight change on the humidity ratio $\omega / \omega_{0}$ inside the fridge occurs, this is due to constant the ambient temperature which means there is no vaporization of water through the system, also both the air velocity and mass flow rate of the two air curtains were constant. The figures show also that, as $\mathrm{x} / \mathrm{b}_{\mathrm{o}}$ increased the humidity ratio $\omega / \omega_{0}$ is increased as mentioned previously. Also, the air entrainment increased as $\mathrm{x} / \mathrm{b}_{\mathrm{o}}$ increases which lead to an increase in the humidity ratio $\omega / \omega_{0}$.

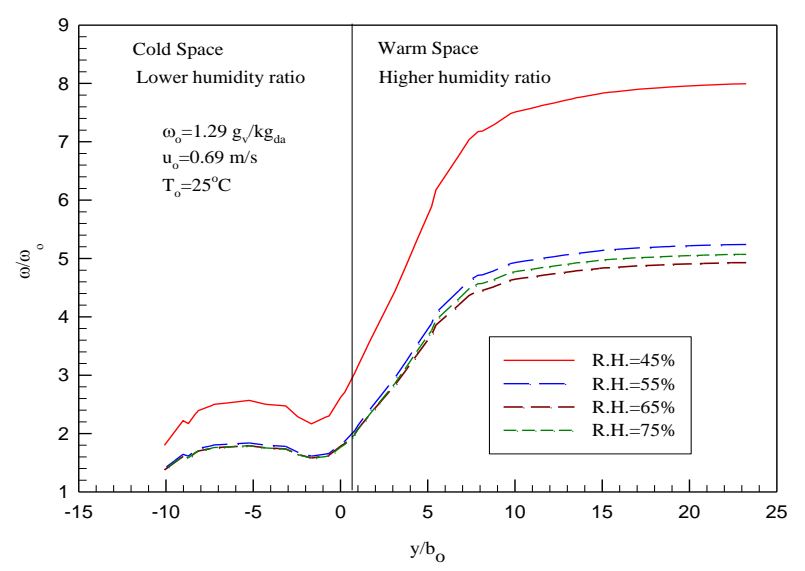

Fig. (12) Effect of relative humidity on humidity ratio distribution through two air curtains, $x / b_{0}=6$

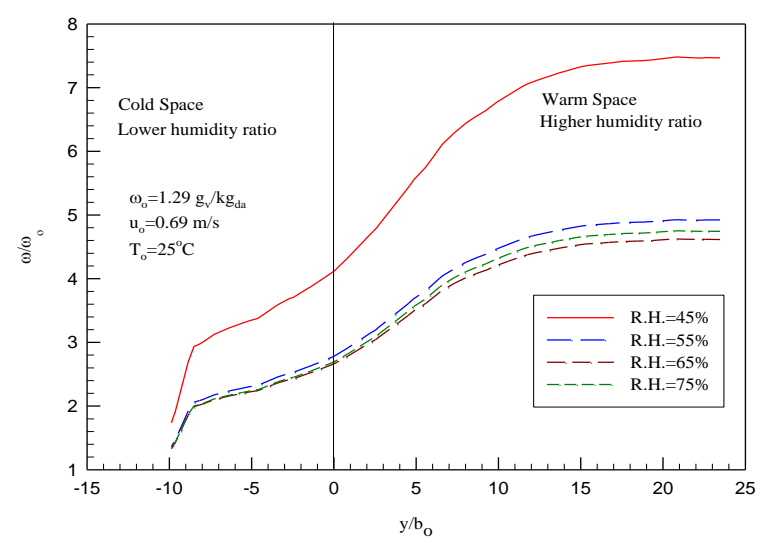

Fig. (13) Effect of relative humidity on humidity ratio distribution through two air curtains, $\mathrm{x} / \mathrm{b}_{\mathrm{o}}=12$.

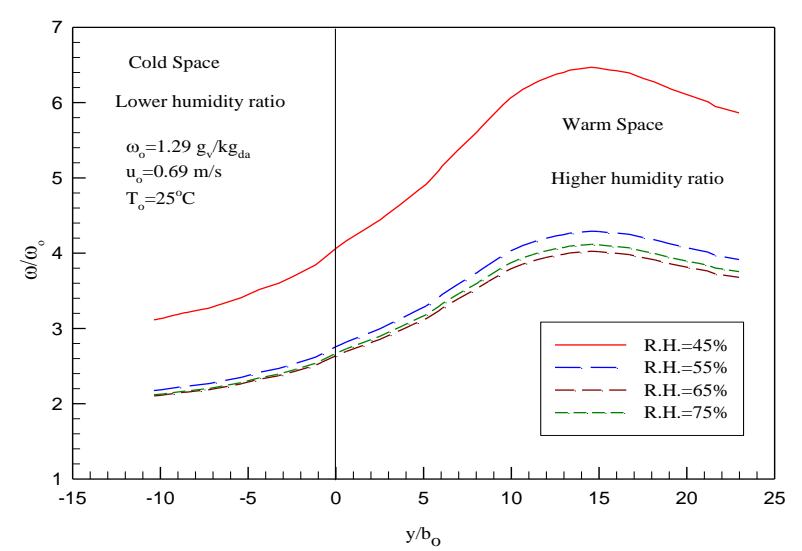

Fig. (14) Effect of relative humidity on humidity ratio distribution through two air curtains, $\mathrm{x} / \mathrm{b}_{\mathrm{o}}=22$. 


\section{4 Heat transfer calculation model}

The entrainment-spill model is similar to that used by Hetsroni [2] for the recirculatory type air curtain. Hetsroni proposed that, the main heat transfer mechanism is due to heated air from the room being entrained into the jet, and then it is cooled, and spilled back into the room again at a lower temperature. The heat transfer rate can be calculated from the velocity and temperature distributions at a jet cross-section just before the impingement point as shown in Fig. (15).

The heat transfer model depends on the effect of temperature and humidity ratio differences between the two sides of the air curtain. As shown in Figs. (1) and (2), the two air curtains can be dealed as one air curtain. The flow pattern of the air curtain can be divided into two parts. The first part is the secondary air entrained from each side (cold space and warm space). This part causes the divergence of the air curtain jet and it spills back at the floor level (with different conditions) to the side from which it comes. Therefore, it causes heat transfer to this side, see Fig. (15). The second part is the primary air that is used in the air curtain outlet which may come from one side of the curtain (cold space and warm space). This air comes with certain conditions ( $T$ and HR) and used in curtain. These conditions will be changed when it spills back at the floor level to the side from which it comes. This change will cause certain heat load on this side.

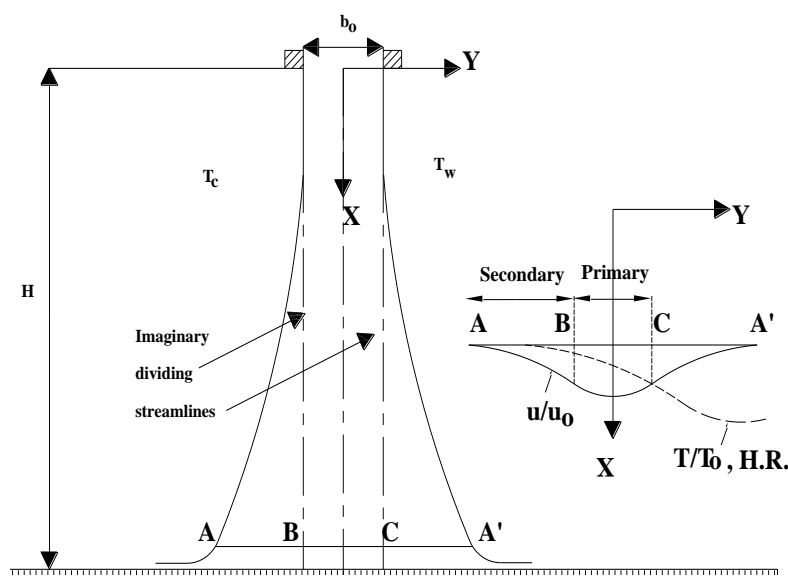

Fig. (15) Description of heat transfer model

Figure (16) represent the value of $(\mathrm{Nu} / \mathrm{Re} . \mathrm{Pr})$ which is an indication of the sensible heat transfer across the two air curtains. Equation (12) could be obtained from curve fitting of Fig. (16).

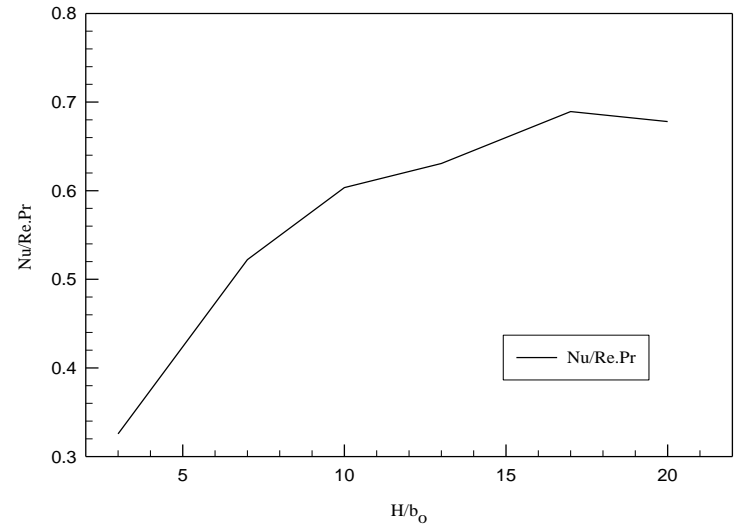

Fig. (16) Variation of $\mathrm{Nu} / \mathrm{Re} \operatorname{Pr}$ with $\mathrm{H} / \mathrm{b}_{\mathrm{o}}$

$$
\begin{aligned}
\frac{N u}{\operatorname{Re} \cdot \operatorname{Pr}} & =0.6069+0.0256 \frac{H}{b_{o}} \\
& -0.00175\left(\frac{H}{b_{o}}\right)^{2}
\end{aligned}
$$

From $\mathrm{Nu} / \mathrm{Re} \mathrm{Pr}$, the value of heat convection coefficient could be obtained as following:

$h=\frac{\rho_{a v} u_{o} b_{o} C_{p}}{H} \frac{N u}{R e \cdot P r}$

The values of $\rho_{\mathrm{av}}$ and $\mathrm{C}_{\mathrm{p}}$ almost constant and equal to $1.15 \mathrm{~kg} / \mathrm{m}^{3}$ and $1.005 \mathrm{KJ} / \mathrm{kg} . \mathrm{K}$ respectively.

The obtained value could be substituted in Eq. (14)

$$
\dot{Q}_{s}=h A \Delta T
$$

Then

$$
\begin{aligned}
\dot{Q}_{s} & = \pm u_{o} b_{o} W\left(T_{w}-T_{c}\right)[0.705 \\
& \left.+0.029 \frac{H}{b_{o}}-0.0021\left(\frac{H}{b_{o}}\right)^{2}\right]
\end{aligned}
$$

Where the positive sign is used for the sensible heat added to cold space and the negative sign is used for the sensible heat lost from the warm space.

\section{5 Latent heat transfer calculations}

The latent heat refers to the entrainment of moisture through air curtains and that produce latent heat of respiration of agricultural products [9]. It was assumed that the products do not contribute to the latent load due to respiration (weight loss), since in the large majority of cases they are fully sealed from the cabinet.Using a mass transfer coefficient $\mathrm{m}_{\text {conv }}, \mathrm{h}_{\text {mass }}$, we can now write:

$$
\begin{aligned}
& \dot{m}_{\text {conv }}=\rho_{\text {av }} h_{\text {mass }}(H W)\left(\omega_{\text {higher }}-\omega_{\text {lower }}\right) \\
& \dot{Q}_{L}=\dot{m}_{\text {conv }} h_{f g}
\end{aligned}
$$


$\mathrm{h}_{\text {mass }}$ is used along with the Sherwood, Schmidt, and Reynolds Numbers. The diffusion coefficient $\mathrm{D}$ is assumed constant and an average value is used for the air density. The latent heat due to evaporation of water is the major part of the enthalpy. hg $=2502+1.84 \times \mathrm{T}$ and (average value of temperatures is $30^{\circ} \mathrm{C}$ ) [9], so $h_{g}$ is equal to $2557.2 \mathrm{~kJ} / \mathrm{kg}$.

Figure (17) represents the value of (Sh/Re Sc) which is an indication of the latent heat transfer across the two air curtains. Equation (18) could be obtained from curve fitting of Fig. (17).

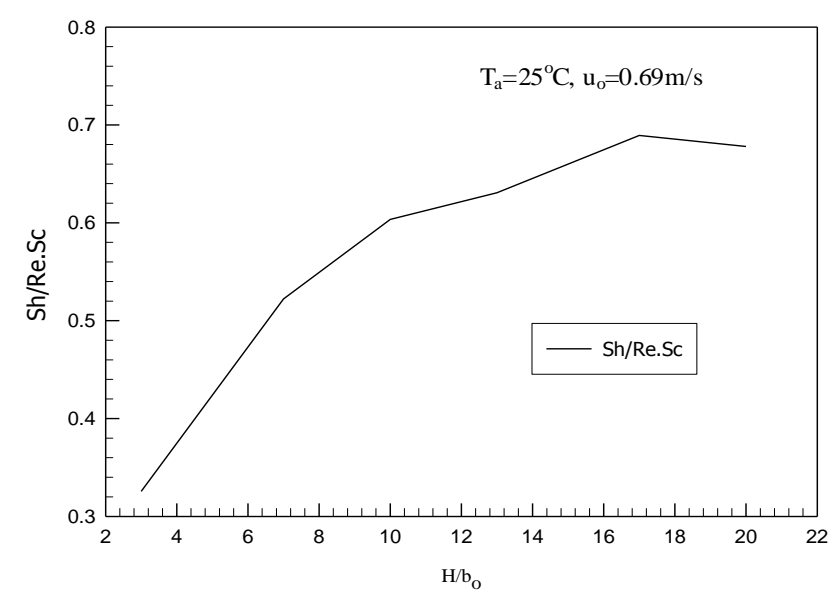

Fig. (17) Variation of Sh/Re .Sc with $\mathrm{H} / \mathrm{b}_{\mathrm{o}}$

$$
\begin{aligned}
\frac{S h}{\operatorname{Re} . S c} & =0.1726+0.0594 \frac{H}{b_{o}} \\
& -0.001714\left(\frac{H}{b_{o}}\right)^{2}
\end{aligned}
$$

From $\mathrm{Sh} / \mathrm{Re} \mathrm{Sc}$ the value of $\mathrm{h}_{\text {mass }}$ could be obtained as following:

$h_{\text {mass }} H=u_{o} b_{o} \frac{S h}{\operatorname{Re} . S c}$

The obtained value could be substituted in Eq. (16). Then

$$
\begin{aligned}
\dot{Q}_{L}= & u_{o} b_{o} \rho_{a v} h_{f g}\left(\omega_{\text {higher }}-\omega_{\text {lower }}\right)[0.1726 \\
& \left.+0.0594 \frac{H}{b_{o}}-0.001714\left(\frac{H}{b_{o}}\right)^{2}\right]
\end{aligned}
$$

\section{6 Relation between heat transfer Stanton number and mass transfer Stanton number}

From Chilton-Colburn analogy. The analogy between heat and mass transfer can be expressed conveniently as following:

$$
\frac{S t}{S t_{\text {mass }}}=\left(\frac{S c}{P r}\right)^{2 / 3} \text { Or }
$$

$$
\begin{aligned}
\frac{h_{\text {heat }}}{h_{\text {mass }}} & =\rho C_{P}\left[\frac{S c}{P r}\right]^{2 / 3} \\
& =\rho C_{P}\left[\frac{\alpha}{D}\right]^{2 / 3}=\rho C_{P} L e^{2 / 3}
\end{aligned}
$$

Where Le is Lewis number, the relation between heat and mass transfer coefficients can be expressed with a good accuracy as:

$h_{\text {heat }} \cong \rho C_{P} h_{\text {mass }} \quad$ (Air-water vapor mixtures)

Where $\rho$ and $C_{p}$ are the density and specific heat of air at mean conditions $\left(\rho . C_{p}\right.$ is the specific heat of air per unit volume). Figure (20) shows the relation between $\mathrm{Nu} / \mathrm{Re} \mathrm{Pr}$ and $\mathrm{Sh} / \mathrm{Re} \mathrm{Sc}$ at different values $\mathrm{H} / \mathrm{b}_{\mathrm{o}}$. It was shown by Fig. (18) that, as $\mathrm{H} / \mathrm{b}_{\mathrm{o}}$ increases, Staton number for both heat and mass transfer is increased and also $\mathrm{Nu} / \mathrm{Re} \mathrm{Pr}$ and $\mathrm{Sh} / \mathrm{Re} \mathrm{Sc}$ values were close to each other.

Figure (19) shows the effect of sensible heat gain through air curtains with different $\mathrm{H} / \mathrm{b}_{\mathrm{o}}$. It is obviously seen that, as $\mathrm{H} / \mathrm{b}_{0}$ and ambient temperatures were increased sensible heat increased due to the entrainment of air from the space. It is clear that the heat transfer through two air curtains was less than one air curtain by about $15 \%$ which leads to a decrease in the power consumption by this value.

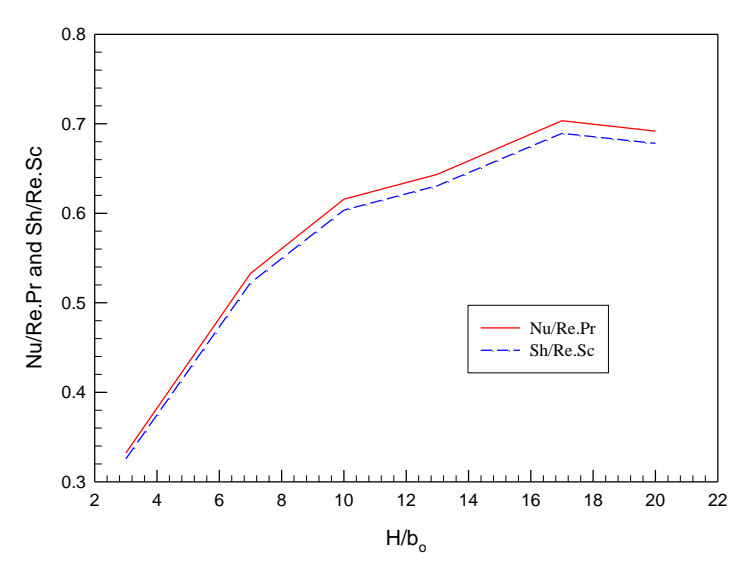

Fig. (18) Relation between $\mathrm{Nu} / \mathrm{Re}$.Pr and $\mathrm{Sh} / \mathrm{Re}$.Sc at different values $\mathrm{H} / \mathrm{b}_{\mathrm{o}}$ 


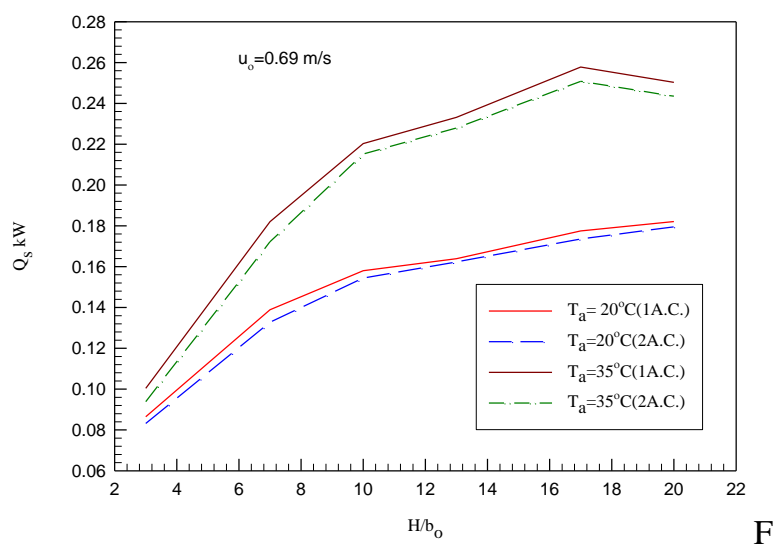

ig. (19) Comparison of $\mathrm{Q}_{\mathrm{s}}$ of one and two air curtains at different values of $\mathrm{H} / \mathrm{b}_{\mathrm{o}}$

Figure (20) illustrates the effect of ambient temperatures on both sensible and latent heat transfer through the air curtains. The results show that an increase in ambient temperature tends to temperature rise inside the cabinet which in turn leads to increase the sensible heat transfer through air curtains. However, it is observed that, the variance of sensible heat inside the cabinet $\left(\mathrm{H} / \mathrm{b}_{\mathrm{o}}<10\right)$ at different ambient temperatures was small, due to using the air curtains with a suitable air velocity which prevent the air infiltration.

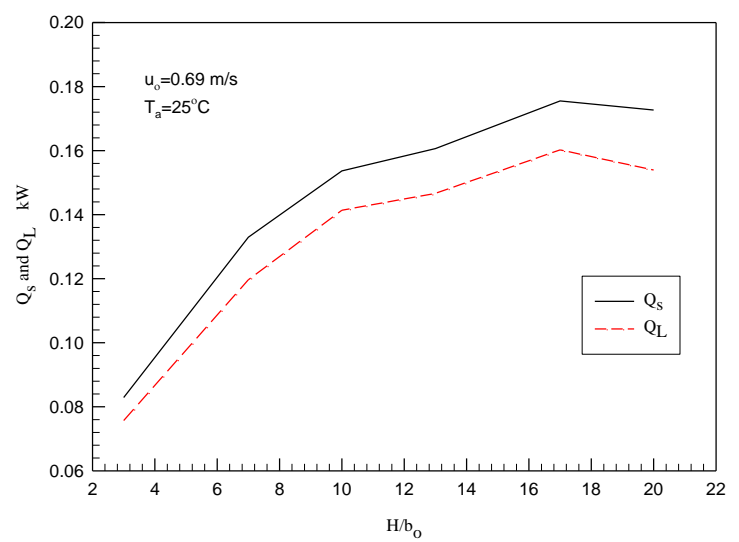

Fig. (20) Relation between $\mathrm{Q}_{\mathrm{S}}$ and $\mathrm{Q}_{\mathrm{L}}$ at different values $\mathrm{H} / \mathrm{b}_{\mathrm{o}}$

\section{7 Comparison between humidity ratio distributions through one and two air curtains}

The simulations were carried out with air curtain temperature of $4.4^{\circ} \mathrm{C}$ which discharge from outlet and ambient temperature $20^{\circ} \mathrm{C}$ and relative humidity $45 \%$ at different $x / b_{o}$ and $y / b_{0}$. The following Figures illustrated the influence of ambient conditions on humidity ratio through one and two air curtains. As shown in the following Figs (21), (22) and (23), it can be seen that the effect of ambient conditions on humidity ratio inside the fridge. It is shown that the humidity ratio inside the fridge is lower in the case of using two air curtains is lower than that in the fridge uses one air curtain. Also, it can be seen that, as $y / b_{o}$ increases the humidity ratio $\omega / \omega_{0}$ is increased for both one and two air curtains.

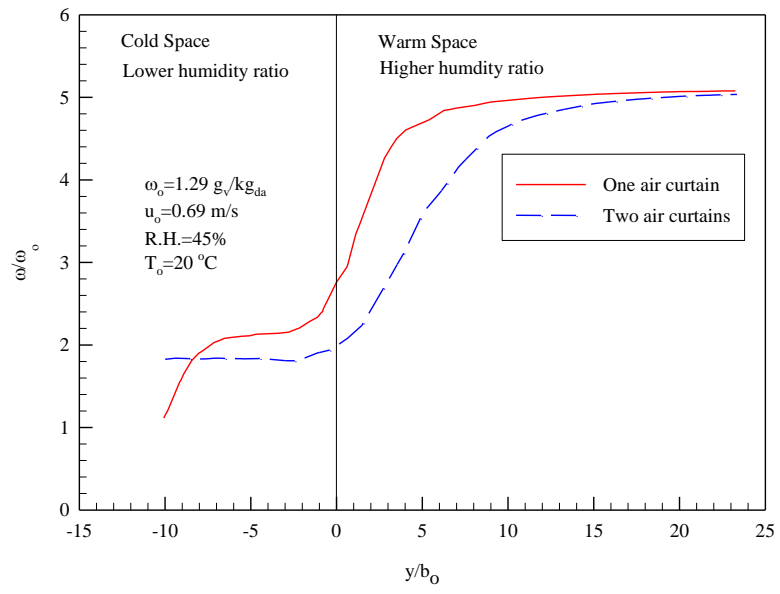

Fig. (21) Comparison of humidity ratio distributions of one and two air curtains at $x / b_{0}=6$

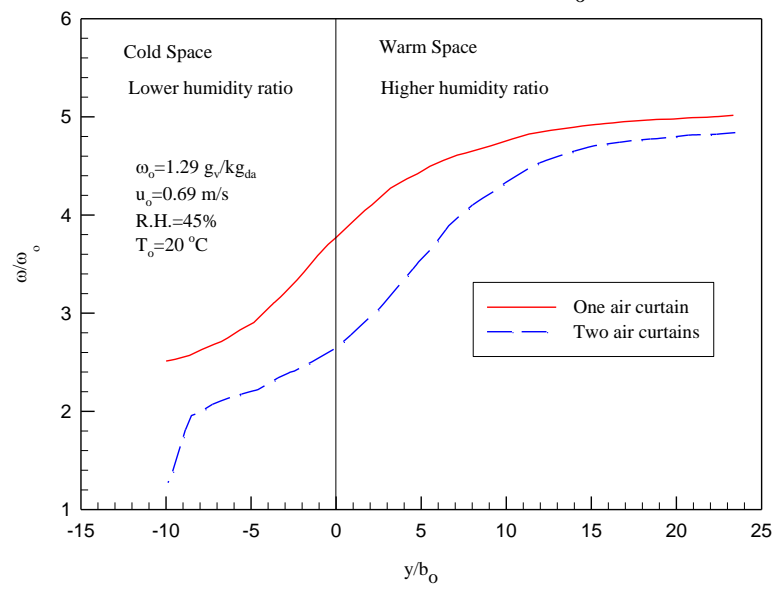

Fig. (22) Comparison of humidity ratio distributions of one and two air curtains at $\mathrm{x} / \mathrm{b}_{\mathrm{o}}=12$

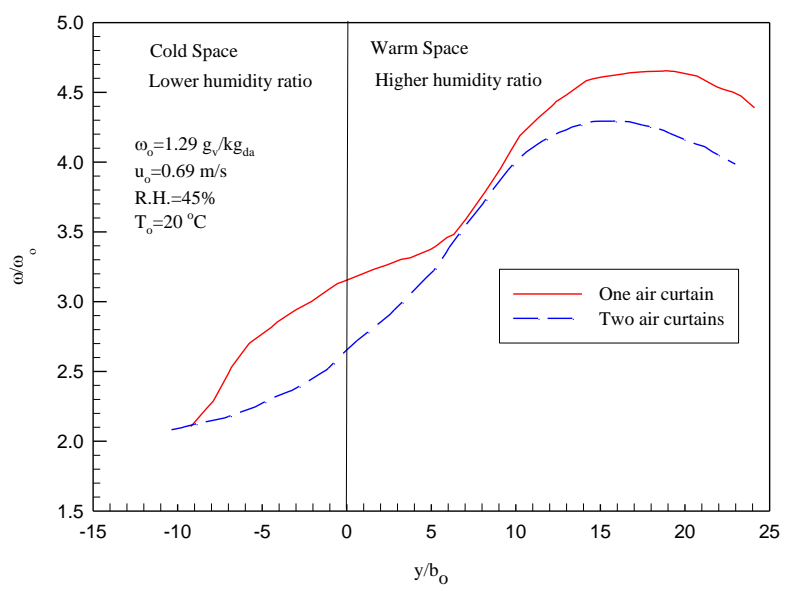

Fig. (23) Comparison of humidity ratio distributions of one and two air curtains at $x / b_{0}=22$

The sensible heat was calculated from Eqs (20) and compared with the results obtained by Verthaeghe [14] and Rey [13]. The comparison is plotted on Figs. (24) and (25). Figure (24) represents the comparison for one air curtain while Fig. (25) represents the 
comparison for two curtains. The Figures indicate agreement between the present work and the other mentioned work. It can be seen from the Figures that, the sensible heat increases when the value $\mathrm{H} / \mathrm{b}_{\mathrm{o}}$ is increased.

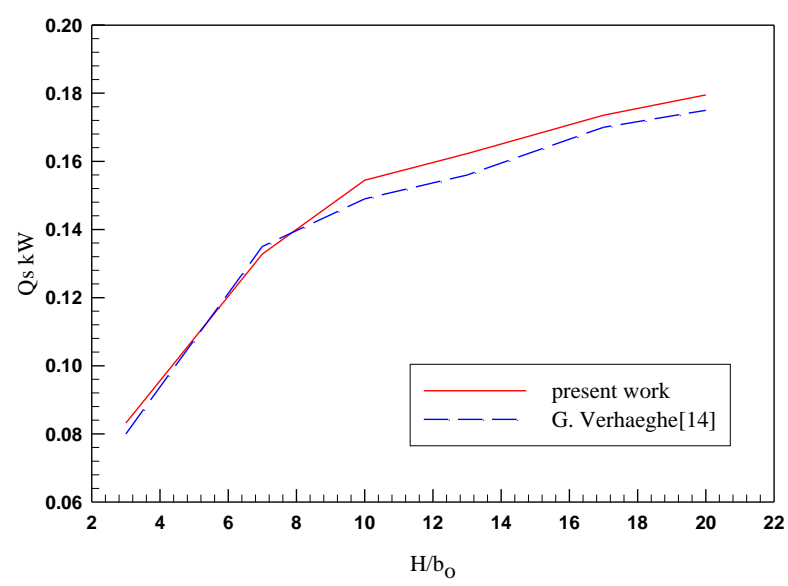

Fig. (24) Variation of $\dot{Q}_{\sigma}$ through one air curtain $\mathrm{H} / \mathrm{b}_{\mathrm{o}}$

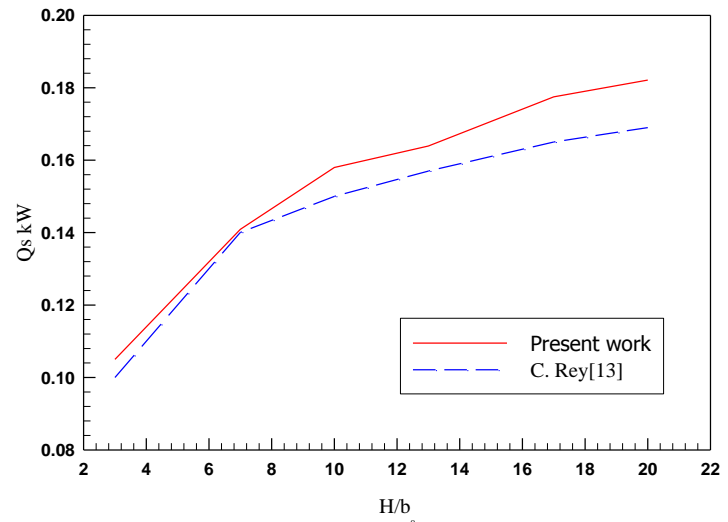

Fig. (25) Variation of $\dot{Q}_{s}$ through two air curtain $\mathrm{H} / \mathrm{b}_{\mathrm{o}}$

\section{Conclusions}

From the analysis of the present study, the following conclusions may be drawn:

1) The increase of ambient relative humidity increases latent and sensible heat load of the fridge.

2) The difference between the refrigerated space and ambient conditions (temperature and humidity ratio) has a great effect on performance of air curtains. To increase the performance of air curtains, the air curtains thickness and velocity should be increased. Also, the use of two air curtains keep the temperature inside the cabinet and increase air curtain performance.

3) By using two air curtains into a display case with different velocities, when the high velocity being on the outside of the air curtain, it has been shown that significant saving on energy by about $15 \%$ are possible.

4) For the case of using the two air curtains the temperature and humidity ratio inside the fridge are

lower than that in the fridge used one air curtain. This led to decrease the power consumption by the unit.

\section{Nomenclature}

Symbol Quantity

A Area, m2

$\mathrm{b}_{\mathrm{o}} \quad$ Jet thickness, $\mathrm{m}$

$\mathrm{Cp} \quad$ Specific heat at constant pressure, $\mathrm{kJ} / \mathrm{kg} . \mathrm{K}$

$\mathrm{H}$ Display cabinet height, $\mathrm{m}$

$\mathrm{k}_{1} \quad$ Fraction, \%

$\mathrm{h}_{\text {mass }} \quad$ Mass transfer coefficient, $\mathrm{m} / \mathrm{s}$

m Product mass, $\mathrm{kg}$

Q $\quad$ Heat transfer, $\mathrm{kW}$

Sc Schmidt Number

$\mathrm{St}_{\text {mass }} \quad$ Mass transfer Stanton number, Sh/Re.Sc

$\mathrm{T} \quad$ Temperature, ${ }^{\circ} \mathrm{C}$

$\mathrm{U}$ Overal heat transfer coefficient, $\mathrm{W} / \mathrm{m}^{2} \mathrm{k}$

$\mathrm{V} \quad$ Volume flow rate of air, $\mathrm{m} 3 / \mathrm{s}$

W Electric load consumed, W

Greek

$\Delta \tau \quad$ Time, $\mathrm{h}$

$\omega \quad$ Humidity ratio, $\mathrm{kg}_{\mathrm{v}} / \mathrm{kg}_{\mathrm{da}}$

\section{Subscripts}

ASH Anti-sweat heater.

Case Display case

C Transmission

D Defrost heater

da Dry air

$\mathrm{f} \quad$ Final

i Final desired

i,1 Infiltration latent

i,s Infiltration sensible

Li Lights

pd Pull-down load due to defrost

pr Product latent heat of respiration

ps Pull-down load due to product shelving

pulldown Product pull-down load

v Vapour 


\section{References}

[1] G. Hetsroni, "Heat transfer through an air curtain", Ph.D. Thesis, Michigan State University, East Lansing, 1963.

[2] F.C. Hayes, "Heat transfer characteristics of the air curtain: a plane jet subjected to transverse pressure and temperature gradient", Ph.D. Thesis, University of Illinois, Urbana, IL, 1968.

[3] N.Q. Van, "Influence of initial turbulence intensity on heat transfer through a recirculated air curtain", Ph.D. Thesis, University of Missouri-Rolla, Rolla, MO, 1975.

[4] E. Hammond, J. Quarini and A. Foster, "Development of a stability model for a vertical single band recirculated air curtain sealing a refrigerated cavity" International journal of refrigeration, Vol. 34,pp 1455-1461, 2011.

[5] LPC Neto, Gameiro MC Silva and JJ.. Costa, "On the use of infrared thermography in studies with air curtain devices". Energy and Buildings, vol 38, pp 1194-1199, 2006.

[6] KZ Yu, GL Ding and TJ Chen, "Simulation of air curtains for vertical display cases with a two-fluid model". Applied Thermal Engineering, vol. 27, pp 2583-2591, 2007.

[7] KJ Ryu, M Juraeva, SH Jeong and DJ Song, "Numerical Simulation in the Air-Curtain Installed Subway Tunnel for the Indoor Air Quality". World Academy of Science, Engineering and Technology, vol. 63, pp 399-403, 2012.

[8] RMJ Bokel, "Smoke separation with Air curtains analysed using CFD-simulations". Proceedings of Clima 2007 WellBeing Indoors.

[9] ASHREA fundamental,1999.

[10] Joseph lai and Asghar Nasr, "Some mean flow characteristics of two parallel plane jets". $13^{\text {th }}$ Australlasian Fluid Mechanics Conference, Monash University, Melbourne, Australia 13-18 December 1998.

[11] FLUENT user's guide, Version 6. FLUENT, Fluent, Inc; 2006.

[12] Wayne C. Turner and Steve Doty "Energy Management Handbook" $6^{\text {th }}$ edition, Published by the Fairmont Press, Inc., 2006.

[13] M. Pavageau, K. Loubière , A. Koched, F. Aloui, J.C. Elicer-Cortés and C. Rey, "Plane turbulent impinging jets", Turbulence, Heat and Mass Transfer 6, 2009 Begell House, Inc.

[14] Gregory Verhaeghe, "Study of air curtains used to restrict infiltration into refrigerated rooms". $7^{\text {th }}$ International conference on Heat Transfer, Fluid Mechanics and Thermodynamics, 2010. 